\title{
d2 Dikkat Testinin Geçerlik ve Güvenirlik Çalışması
}

\author{
Yrd. Doç. Dr. Levent YAYCI \\ Giresun Üniversitesi, Eğitim Bilimleri Bölümü, Güre Yerleșkesi / Türkiye
}

\section{Özet}

Brickenkamp (1981) tarafindan geliştirilen ve zamana bağlı olarak, seçici dikkati ölçen d2 Dikkat Testi'nin 9-10 yaş öğrencileri için geçerlik güvenirlik çalışmasını yapmak ve dikkat problemlerinin en yoğun olarak tanılanmaya başladığı bu yaş grupları için kullanışlı bir ölçme aracının psikometrik özelliklerini istatistiki olarak belirlemek bu çalışmanın temel amacını oluşturmaktadır. Bu amaçla İstanbul Kadıköy İlçesine bağlı beş ilköğretim okulundan toplam 124 öğrenciye araştırmacı tarafından bireysel olarak d2 Dikkat Testi uygulanmıştır. Geçerlik çalışmalarında, öğretmen görüşleri ile d2 Dikkat Testi sonuçları arasındaki ilişki, Şifre Alttesti ile d2 Dikkat Testi arasındaki ilişki ve WISC-R Zekâ Testi alttestleri ile d2 Dikkat Testi arasındaki ilişkiye bakılmıştır. Güvenirlik çalışmaları için test-tekrar test yöntemi kullanılmıştır. Yapılan çalışma sonunda d2 Dikkat Testi’nin psikometrik özelliklerinin kabul edilir düzeyde olduğu ve testin Türkiye'de yürütülecek araştırmalarda kullanılabileceği önerilmektedir.

Anahtar Kelimeler: d2 dikkat testi; Seçici dikkat; Geçerlik; Güvenirlik. 


\title{
A Study on The Validity and Reliability of d2
}

\section{Attention-Tests}

\begin{abstract}
The basic aim of this study is to invesitgate the validity and reliability of d2 attention test for the students at age 9-10, which was developed Brickhenkamp (1981) to measure the time-dependent selective attention as well as to statistically identify the psychometric properties of a useful measurement tool for the groups of 9-10 years of age, during which problems with attention is frequently identifed. For this purpose, the researcher, on an individual basis, performed d2 Attention Test on totally 124 students of five elementary schools in the township of Kadıköy, İstanbul. In the study, the focus is on the realtionship between the teachers' views and d2 Attention Test results, the relationship between Code Sub-Test and d2 Attention Test and the relationship between WISC-R Intelligence Test and d2 Attention Test. The method of test-after-test was used for the reliability-studies. From the results obtained, it can be suggested that the psychometric properties of d2 Attention Test were at an acceptable level and the test could be used for the research to be done in Turkey
\end{abstract}

Keywords: d2 attention-test; Selective attention; Validity; Reliability.

\section{Extended Summary}

\section{Purpose}

In this study, it has been performed a work on the validity and reliability of d2 Attention Test.

\section{Method}

The study on the validity and reliability of $\mathrm{d} 2$ Attention Test is based on the data obtained from the students from five elementary schools at the district of Kadıköy, Istanbul. As data collection instru- 
ments, it has been used, teachers' views, Digit Symbol Coding Subtest and WISC-R Intelligence Test. In the work on validity it has been examined the correlation between the teachers' views and the results of d2 Attention Test, the relationship between the Digit Symbol Coding Subtest and d2 Attention Test and the relationship between WISC-R Intelligence sub-tests and $\mathrm{d} 2$ Attention Test. In the reliability work, the 'Test-retest' method has been utilized.

\section{Findings}

After the tests for the significance of the realtionship between pre-and-post-test scores obtained from test-after-test measurements made for the reliability work, the results obtained from the Pearson Multiplication Moment Correlation Analysis indicated that the correlation under discussion have been found to be $(r=, 831 ; \mathrm{p}<.001)$ for $\mathrm{TN}$ scores, $(\mathrm{r}=, 884 ; \mathrm{p}<.001)$ for E1 scores, $(\mathrm{r}=, 761 ; \mathrm{p}<.001)$ for E2 scores, $(\mathrm{r}=, 831 ; \mathrm{p}<.001)$ for TN-E scores, $(\mathrm{r}=, 877 ; \mathrm{p}<.001)$ for CP scores, $(\mathrm{r}=, 570 ; \mathrm{p}<.001)$ for FR scores, which are considered to be positive and significant. The scores obtained have proved that all the sub-tests of the Attention Test are reliable in respect to continuity.

The results obtained from the non-parametric Mann Whitney-U analysis made for the correlation between teachers' views and the results of d2 Attention Test to be established showed that there existed a statistically significant difference between TN, TN-E, CP sub-dimensions, but did not exist any statistically significant difference between E1, E2, ve FR sub-dimensions. 
The results obtained from the Pearson Multiplication Moment Correlation analysis made in order to determine relationship between the attention-test scores and the Digit Symbol Coding Subtest scores to be determined indicated that there existed a significant and positive correlation not only between the code-scores and the TN Digit Symbol Coding Subtest scores $(r=, 716 ; \mathrm{p}<.001)$ but also between the Digit Symbol Coding Subtest scores and the TN-E scores $(\mathrm{r}=, 679 ; \mathrm{p}<.001)$, between the Digit Symbol Coding Subtest scores and the CP scores ( $\mathrm{r}=$ ,560; $\mathrm{p}<.001)$ as well. The correlation between other scores have not been found to be significant ( $\mathrm{p}>.05)$.

In order to determine the correlation between WISC-R Attention Test sub-tests and d2 Attention Tests, the Pearson multiplication moment correlation analysis has been made and the results obtained have showed that there existed a significant and positive correlations between the TN-E scores and WISC-R total and sub-dimension scores.

\section{Conclusion}

The psychometric characteristics of $\mathrm{d} 2$ Tests are at acceptable level, that is, this test is reliable enough to be used in researches to be done in Turkey.

\section{Giriş}

Psikoloji biliminde dikkat, bireyin duyu organları ile ulaşabildiği, duyu organları ile farkında olduğu fenomenal çevresinde meydana gelen uyarıcıya ya da uyarıcılara, zihinsel alıcılarını yönlendirmesidir (Karakaş, 1997). Dikkat çevredeki birçok uyarandan sadece o anki 
ihtiyaçlar ve amaçlar doğrultusundakilerle ilgilenmeyi sağlayan bir sinir sistemi işlevidir (Kolb ve Winshaw, 1996). Gestalt ekolü ise dikkati, şekil ve zemini ayırabilme yeteneği olarak tanımlamaktadır (Bowe ve Hilgard, 1981).

Dikkatin önemli bir özelliği seçicilik’tir. Her zaman dikkati çekecek birçok uyarıcı vardır. Bu uyarıcıların hepsine odaklanmak imkansız olduğu için bunların hangilerinin önemli olduğu seçilebilmelidir. Seçici dikkat, belirgin olanın saptanarak diğer uyarıcıların ihmal edilmesi ve dikkatin belli bir uyarıcıya yönelmesi; ilgili uyarıcı ile ilgisiz uyarıcıyı ayırabilme ve bir uyarıcılar seti içerisinde ilgisiz uyarıcılara tepkide bulunmayıp yalnızca ilgili uyaranlara tepkide bulunabilmedir (Broadbent, 1958; Sergeant, 1996; Mesulam, 2004).

Dikkatin seçiciliği olmasaydı, organizma çevresinde bulunan pek çok şeye tutarlı bir şekilde davranamazdı. Seçici dikkat düzeyi yüksek olan bireyler özellikle ilgilenmeleri gereken şeylerle ilgilenirken, bu yeteneği düşük olan ya da dikkati dağınık olan bireyler etraflarındaki daha çok uyarıcıyla ilgilenmektedirler. Bu uyarıcıların çoğu da ilgilenmemeleri gereken uyarıcılardır.

Seçici dikkati ölçen veya geliştirmeye çalışan araştırmalar için bu kavramları geçerli ve güvenilir bir şekilde değerlendirebilecek ölçme araçlarına ihtiyaç vardır. Bu araçlardan birisi 1962 yılında Almanya, Essen'de geliştirilmiş olan d2 Dikkat Testi'dir. Bu testte dikkat, konsantrasyon ve algısal hız gibi özellikler görülmeye çalışılmıştır. Testin standardizasyonunu ve bugünkü kullanıma uygun hale getiren kişi ise 
Brickenkamp (1981)'dir.

d2 Dikkat Testi zamana bağl1 olarak, seçici dikkati ölçen bir testtir. Görevin yapılma hızı, kurallara uyum ve performans kalitesi ölçülen alt özelliklerdir (Brieckamp ve Zillmer, 1998). d2 Dikkat Testi'nde uygulanan görsel tarama seçici dikkatin önemli bir bileşenidir (Spreen ve Strauss, 1998).

Test 9-60 yaşlar arasındaki bireylere bireysel veya grup hâlinde uygulanabilir. Bir sayfalık test formunda 14 sira ve her sirada 47 adet olmak üzere toplam 658 figür bulunmaktadır. Testte 'd' ve 'p' harfleri kullanılmaktadır. Bazı harflerin altında veya üstünde toplam bir, iki, üç ve dört nokta bulunmaktadır. Testte harfler, noktaları aldığ sayılarına göre toplam 16 farklı şekilde bulunabilmektedir. Testi alan kişinin temel görevi toplam iki noktası olan 'd' harfini bulabilmektir. Bunlar testte üç farklı şekilde bulunabilmektedir. Testi alana her sırada belirtilen görevi yerine getirebilmesi için 20 sn süre verilmektedir. Testin uygulanma süresi yaklaşık sekiz dakikadır. Grup uygulamalarında hazırlık aşamasında yönergelerin verilmesi, yönergelerin anlaşıldığının kontrolü ve örnek uygulama nedeniyle görev dişında 7-8 dakikaya daha ihtiyaç duyulmaktadır.

Test puanlarının hesaplanması için iki ayrı puanlama anahtarı kullanılmaktadır. Test esnasında altı adet puan elde edilmektedir. Bunlar; TN (işaretlenen toplam figür sayısı), E1 (işaretlenmeden atlanılan figürlerin sayısı), E2 (yanlış işaretlenen figürlerin sayısı), CP (işaretlenen toplam doğruların sayısı), TN-E (test performansı) ve 
E\%'dır (hataların oranı).

Bir ölçme aracında olması gereken en temel özellikler ölçme aracının geçerli ve güvenilir olmasıdır. Güvenirlik/güvenilirlik (reliability), bir ölçme aracıyla farklı zamanlarda yapılan ölçümler arasında aynı sonuçların alınması, sonuçlar arasında tutarlılığın olmasıdır (Linn ve Gronlund, 1995; Meeker, 1998; Ergin, 1995). Bir ölçme aracının güvenirliği için aranılan iki temel ölçüt, 'değişik zamanlarda elde edilen cevaplar (puanlar) arasında tutarlık' ve 'aynı zamanda elde edilen cevaplar arasında tutarlık' olarak açıklanabilir (Carey, 1988; Thorndike ve ark., 1991; Büyüköztürk, 2003).

Güvenirliği düşük olan bir ölçümün, bilimsel değeri de düşük olacaktır (Öner, 1997). Güvenirliği belirleyecek birden çok yöntem vardır. Hangisinin seçileceği maddelerin puanlanmasına, amaca, araştırma koşullarına ve ölçeğin hipotezlerine bağlı olarak değişir (Tezbaşaran, 1997). Güvenirlik katsayıları genellikle korelasyon katsayıları ile hesaplanır. $\mathrm{Bu}$ çalışmada güvenirlik katsayısı hesaplama yöntemi olarak devamlılık katsayısı (test-tekrar-test güvenirliği) kullanılmıştır.

Geçerlik ise bir ölçme aracının ölçülmek üzere hazırlandığı amacı, değişkeni ölçme derecesidir. Ölçme işlemi yapılırken ölçme aracının başka bir özelliği değil, sadece ölçmek istediği özelliği tam ve doğru ölçmesidir (Ergin, 1995; Büyüköztürk ve ark., 2008) Ölçmede sık kullanılacak geçerlik türleri; kapsam geçerliği, yapı geçerliği, ölçüt-bağımlı geçerlik, eşzaman geçerliği ve yordama geçerliğidir. Bu çalışmada kriter geçerliği için WISC-R Zekâ Testi alttestleri ile d2 
dikkat arasındaki ilişki ve şifre (WISC-R alttesti) testi ile d2 Dikkat Testi arasındaki ilişkiye ayırdedicilik analizi olarak öğretmen görüşleri ile d2 Dikkat Testi sonuçları arasındaki ilişkiye bakılmıştır.

d2 Dikkat Testi'nin Türkiye'ye adaptasyonu ve norm çalışması Toker (1993) tarafından yapılmıştır. Sözkonusu testin 11-14 yaş İstanbul çocukları için güvenirliği yüksek bulunmakla birlikte geçerliliği konusunda ilave çalışmalar yapılması önerilmiştir. İstatistikî olarak manidar bir fark görülmemekle birlikte kızların test performansının erkeklere göre daha iyi olduğu görülmüştür. İki yarım güvenirliği .94 bulunmuştur. Geçerlik çalışmasında ise WISC-R şifre altesti ile toplam puan arasında .44 korelasyon bulunmuştur. Öğretmenlerin çocukların aktif veya pasif olması ile psiko-motor hıları ve irade-dayanıklılık (kolay pes etmeme) ile hata yapma oranları arasındaki yordamaları konusunda düşük korelasyonlar elde edilmiştir ( $\mathrm{r}=.10$ ve $\mathrm{r}=.16) \mathrm{Bu}$ durum öğretmenlerin dikkat konusunu nasıl yorumladıkları konusunda literatür ile paralel olmayan yargıları olduğuna bağlanmıştır.

Çağlar (2003) tarafindan d2 testinin Türk sporcuları için güvenirlik ve geçerliğini belirlemek amacıyla değişik spor dallarından 701 sporcu üzerinde yapılan çalışmada ise d2 Dikkat Testi’nin yanısıra ölçüt bağıntılı geçerlik çalışması için Stroop Testi TBAG Formu ve İşaretleme Testi, test-tekrar test prosedürü için 15, 30 ve 90 gün aralarla d2 Dikkat Testi uygulamıştır. d2 Dikkat Testi puanlarında değişik aralıklarla yapılan uygulamalar arasındaki fark incelendiğinde test tekrarlarının yapılmasıyla seçici ve sürekli dikkat ile ilgili puanların [Toplam Madde (TN), TN-E (Toplam Madde-Hata), CP (Konsantras- 
yon Performansı)] arttığı, hatalara ilişkin puanların [Toplam Hata (H) ve Hata Yüzdesi (\% H)] ve Dalgalanma Oranının (FR) azaldığ1 görülmüştür. d2 Testi puanlarının sınıfiçi güvenirlik katsayıları arasında en yüksek güvenirlik katsayısının $\mathrm{R}=.86$ ile $\mathrm{TN}$ puanına ve en düşük güvenirlik katsayısının ise $\mathrm{R}=.69$ ile $\mathrm{CP}$ puanına ait olduğu bulunmuştur. d2 Dikkat Testi puanlarının iki yarıya bölme güvenirlik katsayıları .91 ile .96 arasında, Cronbach alfa iç tutarlık katsayıları ise .93-.96 arasında değişmediği belirtilmiştir.

Ölçüt bağıntılı geçerlik için verilere uygulanan Pearson korelasyon testi sonucunda d2 Dikkat Testi'nin TM, TM-H ve KP puanlan ile Stroop Testi TBAG Formu (-.19 ile -.36 arasında; $\mathrm{p}<.05)$ ve İşaretleme Testi (-.36 ile -.53 arasında; $\mathrm{p}<.05)$ süre puanları arasında negatif ve istatistiksel olarak anlamlı korelasyonlar bulunmuştur. d2 Dikkat Testi puanlarında cinsiyetler arasında anlamlı fark bulunmamıştır.

Sonuç olarak; d2 Dikkat Testi’nin Türk sporcularında güvenirliği ve geçerliğinin yükssek olduğu ve dikkat performansını değerlendirmek amacıyla hem araştırmalarda hem de uygulamada kullanılabileceği belirtilmiştir.

11-14 yaş grubu geçerlik ve güvenirlik çalışmaları Toker (1993) tarafından yapılan d2 Dikkat Testi'nin 9-10 yaş öğrencileri için geçerlik güvenirlik çalışmasını yapmak ve dikkat problemlerinin en yoğun olarak tanılanmaya başladığı bu yaş grupları için kullanışlı bir ölçme aracının psikometrik özelliklerini istatistiki olarak belirlemek bu çalışmanın temel amacını oluşturmaktadır. Ülkemizde bu yaş grubu öğ- 
rencilerinin seçici ve yoğunlaştırılmış dikkat düzeyini ölçen, geçerlik ve güvenirlik çalışması yapılmış ölçme aracının olmaması nedeniyle ilgili çalışmanın alana katkı sağlayacağı düşünülmektedir.

\section{Yöntem}

\section{Çalışma Grubu}

d2 Dikkat Testi'nin geçerlik ve güvenirlik çalışması İstanbul Kadıköy İlçesi’ne bağlı beş ilköğretim okulundan 4. sınıf düzeyinde toplam 124 öğrenciden alınan veriler üzerine yapılmıştır. Test her okulun 4. sınıfının değişik şubelerinden tesadüfi olarak alınmış 25 'er öğrenciye uygulayıcı tarafından bireysel olarak uygulanmıştır. Bir öğrencinin testi yönergeye tam olarak uyulmaması nedeniyle değerlendirme dişında tutulmuştur.

Öntest uygulamaları yaklaşık yirmi gün içinde tamamlanmıştır. Sontest uygulamaları ise ilk uygulamadan iki ay sonra yapılmıştır.

\section{Veri Toplama Araçları}

Araştırmada veri toplama araçları olarak d2 Dikkat Testi'nin yanı sıra WISC-R Zekâ Testi ve Öğretmen Görüşü Formu kullanılmıştır.

\section{WISC-R Zekâ Testi}

Veri toplamada kullanılan birinci araç WISC-R Zekâ Testi'dir. Alttestlerinde değişik yetenek alanlarından örnekler bulunması, yorum ve puanlama esaslarının belirginliği, psikometrik özelliklerinin doyuruculuğu, bu ölçeğin tercih edilmesine katkıda bulunmaktadır. Ölçek 1949 yılında D.Wechsler tarafından geliştirilmiş ve 1974 yılında yeniden gözden geçirilmiştir. 1982 yılında Hacettepe Üniversitesi öğre- 
tim elemanlarınca Türkiye norm çalışması yapılmıştır. Test 12 alttestten oluşmakta ve 6-16 yaş arasındaki bireylere uygulanabilmektedir. Uygulama bireysel olarak yapılmakta ve yaklaşık 1-1.5 saat civarında sürmektedir (Savaşır ve Şahin, 1995).

Test genel olarak sözel ve performans olmak üzere iki bölümden oluşmaktadır. Her bir bölüme ilişkin altışar alttest bulunmaktadır. Sözel bölüme ait alt testler; genel bilgi, benzerlikler, aritmetik, sözcük dağarcığı, yargılama ve sayı dizisi alt testleridir. Performans bölüme ait alt testler; resim tamamlama, resim düzenleme, küplerle desen, parça birleştirme, şifre ve labirentler alt testleridir.

\section{Öğretmen Görüşü Formu}

Öğretmenlerden geçerlik çalışmasında kullanılmak üzere oluşturulmuş öğretmen görüşü formlarını doldurmaları istenmiştir. $\mathrm{Bu}$ formlara öğretmenler sınıflarında en aktif, en pasif ve dayanıklı (kolay pes etmeyen-sebatlı) ve dayanıklı olmayan üçer öğrenciyi yazmışlardır.

\section{İşlem}

Çalışmanın temel işlem süreci çalışma grubunun belirlenmesinden sonra güvenirlik ve geçerlik çalışmasına ait verilerin toplanmasıdır.

\section{Güvenirlik ve Geçerlik Çalışmasına Ait Verilerin Toplanması}

Güvenirlik çalışmaları için test-tekrar-test yöntemi kullanılmıştır. Geçerlik çalışmaları için testin orijinalinde olduğu gibi öğretmen görüşü, Şifre altesti ve WISC-R Zekâ Testi kullanılmıştır. Öğretmen görüşleri ile d2 Dikkat Testi sonuçları arasındaki ilişki, şifre testi ile d2 Dikkat Testi arasındaki ilişki ve WISC-R Zekâ Testi alttestleri ile d2 
Dikkat Testi arasındaki ilişki araştırılmıştır.

d2 testi göz kamaştırıcı etkileri olmayan yeteri derecede aydınlatılmış, yeterli ısıda (oda sıcaklığı) ve gürültüden uzak bir odada bireysel olarak uygulanmıştır. Her bir uygulama yaklaşık 10 dakika sürmüştür.

Öntest uygulamalarından bir hafta sonra ise geçerlik çalışmasına başlanmış ve öğrencilere iki aylık süre içerisinde WISC-R Zekâ Testi şifre alt testi bireysel olarak uygulanmıştır. Ayrıca öğretmenlerden geçerlik çalışmasında kullanılmak üzere oluşturulmuş öğretmen görüşü formlarını doldurmaları istenmiştir. Sekiz farklı sınıf öğretmeninden form doldurmaları istenmiş, sonuçta her bir kategoriye giren (örneğin, kolay pes etmeyen-sebatl1) toplam 24'er öğrenci rapor edilmiştir. Dayanıklılık kategorisinde iki öğretmen belirtilen kategoriye uyan üçer öğrenci olmadığını belirterek daha az sayıda öğrenci rapor etmişlerdir. Dolayısıyla dayanıklı (çabuk pes etmeyen-iradeli) öğrenciler için toplam 23, dayanıksız öğrenciler için 22 öğrenci rapor edilmiştir.

Geçerlik ile ilgili üçüncü ölçüt WISC-R Zekâ Testi alt test sonuçları ile d2 Dikkat Testi sonuçlarının karşılaştırılması olmuştur.

\section{Verilerin Değerlendirilmesi}

Yapılan çalışmada kriter geçerliği için WISC-R Zekâ Testi alt testleri ile d2 dikkat arasındaki ilişki ve şifre (WISC-R alttesti) testi ile d2 Dikkat Testi arasındaki ilişkiye bakılmıştır. Ayırdedicilik analizi olarak öğretmen görüşleri ile d2 Dikkat Testi sonuçları arasındaki ilişkiye bakılmıştır. 
WISC-R Zekâ Testi alt testleri ile d2 dikkat arasındaki ilişki ve şifre testi ile d2 Dikkat Testi arasındaki ilişki Pearson Momentler Çarpımı Korelasyon Katsayısı ile değerlendirilmiştir.

Geçerliği belirlemede ikinci ölçüt olan öğretmen görüşleri ile d2 Dikkat Testi arasındaki farklılık ilişkisiz örneklemler için Mann Whitney U testi ile değerlendirilmiştir. Mann Whitney U testi ilişkisiz ölçümlerin sözkonusu olduğu az denekli deneysel çalışmalarda puanların dağılımının normallik varsayımını karşılamadığı deneysel çalışmalarda sıklıkla kullanılmaktadır (Büyüköztürk, 2003).

\section{Güvenirliğe Ait Verilerin Değerlendirilmesi}

Yapılan çalışmada dikkat testinin tutarlılık (devamlılık) katsayısını belirlemek için test-tekrar-test yöntemi kullanılmıştır.

\section{Bulgular}

\section{Geçerliğe Ait Bulgular}

Geçerlik çalışmaları için öğretmen görüşleri ile d2 Dikkat Testi sonuçları arasındaki ilişki, şifre testi ile d2 Dikkat Testi arasındaki ilişki ve WISC-R Zekâ Testi alttestleri ile d2 Dikkat Testi arasındaki ilişkiye bakılmıştır.

\section{WISC-R Testi Alttestleri ile d2 Puanlarının Karşılaştırılması}

Tablo 1. d2 Dikkat Testi TN-E Puanları ile WISC-R Toplam ve Alt Boyutu Puanları Arasındaki İlişkiyi Belirlemek Üzere Yapılan Pearson Çarpım Moment Korelasyon Analizi Sonuçları 


\begin{tabular}{|l|c|c|c|}
\hline \multirow{2}{*}{ WISC-R Alt Boyutları } & \multicolumn{3}{|c|}{ TN-E Puanları } \\
\cline { 2 - 4 } & $\boldsymbol{N}$ & $\boldsymbol{r}$ & $\boldsymbol{P}$ \\
\hline $\begin{array}{l}\text { Genel Bilgi } \\
\text { Alt Boyutu }\end{array}$ & 40 &, 590 &, 000 \\
\hline $\begin{array}{l}\text { Benzerlikler } \\
\text { Alt Boyutu }\end{array}$ & 40 &, 515 &, 001 \\
\hline $\begin{array}{l}\text { Aritmetik } \\
\text { Alt Boyutu }\end{array}$ & 40 &, 627 &, 000 \\
\hline $\begin{array}{l}\text { Yargılama } \\
\text { Alt Boyutu }\end{array}$ & 40 &, 485 &, 002 \\
\hline $\begin{array}{l}\text { Sayı Dizisi } \\
\text { Alt Boyutu }\end{array}$ & 40 &, 448 &, 004 \\
\hline $\begin{array}{l}\text { Sözel IQ } \\
\text { Alt Boyutu }\end{array}$ & 40 &, 666 &, 000 \\
\hline $\begin{array}{l}\text { Resim Tamamlama } \\
\text { Alt Boyutu }\end{array}$ & 40 &, 657 &, 000 \\
\hline $\begin{array}{l}\text { Resim Düzenleme } \\
\text { Alt Boyutu }\end{array}$ & 40 &, 567 &, 000 \\
\hline $\begin{array}{l}\text { Parça Birleştirme } \\
\text { Alt Boyutu }\end{array}$ & 40 &, 508 &, 001 \\
\hline $\begin{array}{l}\text { Şifre } \\
\text { Alt Boyutu }\end{array}$ & 40 &, 542 &, 000 \\
\hline $\begin{array}{l}\text { Küplerle Desen } \\
\text { Alt Boyutu }\end{array}$ & $\begin{array}{l}\text { Alt Boyutu } \\
\text { Performans IQ }\end{array}$ &, 690 &, 000 \\
\hline $\begin{array}{l}\text { IQ } \\
\text { Alt Boyutu }\end{array}$ & 40600 \\
\hline
\end{tabular}

TN-E puanları ile WISC-R toplam ve alt boyutu puanları arasında anlamlı bir ilişki olup olmadığını belirlemek üzere yapılan Pearson çarpım moment korelasyon analizi sonucunda, TN-E puanları ile 
WISC-R GB $(r=, 590 ; p<.001)$; Benzerlikler $(r=, 515 ; p<.01)$; Aritmetik $(r=, 627 ; p<.001)$; Yargilama $(r=, 485 ; p<.01)$; Say1 Dizisi $(r=, 448 ; p<.01)$; Sözel IQ $(r=, 666 ; p<.001)$; Resim Tamamlama $(r=, 657 ; p<.001)$; Resim Düzenleme $(r=, 567 ; p<.001)$; Parça Birleştirme $(r=508 ; p<.01)$; Şifre $(r=, 542 ; p<.001)$; Küplerle Desen $(r=, 523 ; p<.01)$; Performans IQ $(r=, 676 ; p<.001)$ ve IQ $(r=, 690$; $p<.001)$ alt boyutları arasında pozitif yönlü anlamlı ilişkiler olduğu saptanmıştır.

Tablo 2. d2 Dikkat Testi CP Puanları ile WISC-R Toplam ve Alt Boyutu Puanları Arasındaki İlişkiyi Belirlemek Üzere Yapılan Pearson Çarpım Moment Korelasyon Analizi Sonuçları

\begin{tabular}{|l|c|c|c|}
\hline \multirow{2}{*}{ WISC-R Alt Boyutları } & \multicolumn{3}{|c|}{ CP Puanları } \\
\cline { 2 - 4 } & $\boldsymbol{N}$ & $\boldsymbol{r}$ & $\boldsymbol{P}$ \\
\hline $\begin{array}{l}\text { Genel Bilgi } \\
\text { Alt Boyutu }\end{array}$ & 40 &, 598 &, 000 \\
\hline $\begin{array}{l}\text { Benzerlikler } \\
\text { Alt Boyutu }\end{array}$ & 40 &, 523 &, 001 \\
\hline $\begin{array}{l}\text { Aritmetik } \\
\text { Alt Boyutu }\end{array}$ & 40 &, 690 &, 000 \\
\hline $\begin{array}{l}\text { Yarglama } \\
\text { Alt Boyutu }\end{array}$ & 40 &, 486 &, 001 \\
\hline $\begin{array}{l}\text { Sayı Dizisi } \\
\text { Alt Boyutu }\end{array}$ & 40 &, 487 &, 001 \\
\hline $\begin{array}{l}\text { Sözel IQ } \\
\text { Alt Boyutu }\end{array}$ & 40 &, 695 &, 000 \\
\hline $\begin{array}{l}\text { Resim Tamamlama } \\
\text { Alt Boyutu }\end{array}$ & 40 &, 655 &, 000 \\
\hline $\begin{array}{l}\text { Resim Düzenleme } \\
\text { Alt Boyutu }\end{array}$ & 40 &, 619 &, 000 \\
\hline $\begin{array}{l}\text { Parça Birleştirme } \\
\text { Alt Boyutu }\end{array}$ & 40 &, 550 &, 000 \\
\hline
\end{tabular}




\begin{tabular}{|l|c|c|c|}
\hline $\begin{array}{l}\text { Şifre } \\
\text { Alt Boyutu }\end{array}$ & 40 &, 577 &, 000 \\
\hline $\begin{array}{l}\text { Küplerle Desen } \\
\text { Alt Boyutu }\end{array}$ & 40 &, 529 &, 000 \\
\hline $\begin{array}{l}\text { Performans IQ } \\
\text { Alt Boyutu }\end{array}$ & 40 &, 706 &, 000 \\
\hline $\begin{array}{l}\text { IQ } \\
\text { Alt Boyutu }\end{array}$ & 40 &, 723 &, 000 \\
\hline
\end{tabular}

CP puanları ile WISC-R toplam ve alt boyutu puanları arasında anlamlı bir ilişki olup olmadığını belirlemek üzere yapılan Pearson çarpım moment korelasyon analizi sonucunda, TN-E puanları ile WISC-R GB $(r=, 598 ; p<.001)$; Benzerlikler $(r=, 523 ; p<.01)$; Aritmetik $(r=, 690 ; p<.001)$; Yargılama $(r=, 486 ; p<.01)$; Say1 Dizisi $(r=, 487 ; p<.01)$; Sözel IQ $(r=, 695 ; p<.001)$; Resim Tamamlama $(r=, 655$; $p$ <.001); Resim Düzenleme $(r=, 619$; $p<.001)$; Parça Birleştirme $(r=550 ; p<.01)$; Şifre $(r=, 577 ; p<.001)$; Küplerle Desen $(r=, 529 ; p<.001)$; Performans IQ $(r=, 706 ; p<.001)$ ve IQ $(r=, 723$; $p<.001)$ alt boyutları arasında pozitif yönlü anlamlı ilişkiler olduğu saptanmıştır.

\section{Öğretmen Görüşleri ile d2 Dikkat Testi Sonuçları Karşılaştırması}

\section{Aktiflik-Pasiflik Açısından Karşılaştırma}

Tablo 3. Toplam İşaretleme Sayısı Puanlarının Aktivite Değişkenine Göre Farklılaşıp Farklılaşmadığını Belirlemek Amacıyla Yapılan Non-Parametrik Mann Whitney-U Testi Sonuçları 


\begin{tabular}{|l|l|l|l|l|l|l|}
\hline Grup & $\mathbf{N}$ & $\bar{x}_{\text {sira }}$ & $\sum_{\text {Sira }}$ & $U$ & $z$ & $p$ \\
\hline Aktifler & 24 & 31,56 & 757,50 & & & \\
\cline { 1 - 5 } Pasifler & 24 & 17,44 & 418,50 & \multirow{2}{*}{118,500} & $-3,495$ &, 000 \\
\cline { 1 - 4 } Toplam & 48 & & & & & \\
\hline
\end{tabular}

Tabloda görüldüğü üzere, toplam işaretleme sayısı puanlarının aktivite değişkenine göre farklılaşıp farklılaşmadığını belirlemek amaciyla yapılan non-parametrik Mann Whitney-U analizi sonucunda, aktif olan ve olmayan öğrencilerin sıralamalar ortalaması arasındaki farklılık istatistiksel olarak anlamlı bulunmuştur $(z=-3,495 ; p<.001)$. Söz konusu farkl1lık aktif olan grubun lehine gerçekleşmiştir. Aktif olarak tanımlanan grubun toplam işaretleme sayısının pasif olarak tanımlanan grubun sayısından anlamlı şekilde yüksek çıktığı belirlenmiştir.

Tablo 4. d2 Dikkat Testi Birinci Tür Hata (İşaretlemesi Gerekirken İşaretlemeden Atladığı d'ler) Puanlarının Aktivite Değişkenine Göre Farklılaşıp Farklılaşmadığını Belirlemek Amacıyla Yapılan Non-Parametrik Mann Whitney-U Testi Sonuçları

\begin{tabular}{|l|l|l|l|l|l|l|}
\hline Grup & $\mathbf{N}$ & $\bar{x}_{\text {sira }}$ & $\sum_{\text {Sira }}$ & $U$ & $z$ & $p$ \\
\hline Aktifler & 24 & 21,00 & 504,00 & & & \\
\cline { 1 - 4 } Pasifler & 24 & 28,00 & 672,00 & 204,000 & $-1,738$ &, 082 \\
\cline { 1 - 4 } Toplam & 48 & & & & & \\
\hline
\end{tabular}

Tabloda görüldüğü üzere, birinci tür hata (işaretlemesi gerekirken 
işaretlemeden atladığı d'ler) puanlarının aktivite değişkenine göre farklılaşıp farklılaşmadığını belirlemek amacıyla yapılan non-parametrik Mann Whitney-U analizi sonucunda, aktif olan ve olmayan öğrencilerin sıralamalar ortalaması arasındaki farklılık istatistiksel olarak anlamlı bulunmamıştır $(z=-1,738 ; p>.05)$.

Tablo 5. d2 Dikkat Testi İkinci Tür Hata (İşaretlememesi Gerekirken İşaretlemiş Olduğu Figürler) Puanlarının Aktivite Değişkenine Göre Farklılaşıp Farklılaşmadığını Belirlemek Amacıyla Yapılan Non-Parametrik Mann Whitney-U Testi Sonuçları

\begin{tabular}{|l|l|l|l|l|l|l|}
\hline Grup & $\mathbf{N}$ & $\bar{x}_{\text {sira }}$ & $\sum_{\text {Sira }}$ & $U$ & $z$ & $p$ \\
\hline Aktifler & 24 & 21,50 & 516,00 & & & \\
\cline { 1 - 4 } Pasifler & 24 & 27,50 & 660,00 & 216,000 & $-1,495$ &, 135 \\
\cline { 1 - 4 } Toplam & 48 & & & & & \\
\hline
\end{tabular}

Tabloda görüldüğü üzere, ikinci tür hata (işaretlememesi gerekirken işaretlemiş olduğu figürler) puanlarının aktivite değişkine göre farklılaşıp farklılaşmadığını belirlemek amacıyla yapılan non-parametrik Mann Whitney-U analizi sonucunda, aktif olan ve olmayan öğrencilerin sıralamalar ortalaması arasındaki farklılık istatistiksel olarak anlamlı bulunmamıştır $(z=-1,495 ; p>.05)$.

Tablo 6. d2 Dikkat Testi TN-E (Toplamdan Hataların Çıkarılmış Hâli) Puanlarının Aktivite Değişkenine Göre Farklılaşıp Farklılaşmadığını Belirlemek İçin Yapılan Non-Parametrik Mann Whitney-U Testi Sonuçları 


\begin{tabular}{|l|c|c|c|c|c|c|}
\hline Grup & $\mathbf{N}$ & $\bar{x}_{\text {sira }}$ & $\sum_{\text {Sira }}$ & $U$ & $z$ & $p$ \\
\hline Aktifler & 24 & 33,08 & 794,00 & & & \\
\hline Pasifler & 24 & 15,92 & 382,00 & 82,000 & $-4,248$ &, 000 \\
\cline { 1 - 4 } Toplam & 48 & & & & & \\
\hline
\end{tabular}

Tabloda görüldüğü üzere, TN-E (toplamdan hataların çıkarılmış hali) puanlarının aktivite değişkine göre farklılaşıp farklılaşmadığını belirlemek amacıyla yapılan non-parametrik Mann Whitney-U analizi sonucunda, aktif olan ve olmayan öğrencilerin sıralamalar ortalaması arasındaki farklılık istatistiksel olarak anlamlı bulunmuştur $(z=-4,248$; $p<.001)$. Söz konusu farklılık aktif olan grubun lehine gerçekleşmiştir. Yani aktif olarak tanımlanan grubun TN-E (toplam işaretlemelerden hataların çıkarılmış hali) puanlarının pasif olarak tanımlanan gruptan anlamlı şekilde yüksek çıktığı belirlenmiştir.

Tablo 7. d2 Dikkat Testi CP (Konsantrasyon Performansı) Puanlarının Aktivite Değişkenine Göre Farklılaşıp Farklılaşmadığını Belirlemek Amacıyla Yapılan Non-Parametrik Mann Whitney-U Testi Sonuçları

\begin{tabular}{|l|c|c|c|c|c|c|}
\hline Grup & $\mathbf{N}$ & $\bar{x}_{\text {sira }}$ & $\sum_{\text {Sira }}$ & $U$ & $z$ & $p$ \\
\hline Aktifler & 24 & 34,04 & 817,00 & & & \\
\cline { 1 - 4 } Pasifler & 24 & 14,96 & 359,00 & 59,000 & $-4,723$ &, 000 \\
\hline Toplam & 48 & & & & & \\
\hline
\end{tabular}

Tabloda görüldüğü üzere, CP (konsantrasyon performansı) pu- 
anlarının aktivite değişkenine göre farklılaşıp farklılaşmadığını belirlemek amacıyla yapılan non-parametrik Mann Whitney-U analizi sonucunda, aktif olan ve olmayan öğrencilerin sıralamalar ortalaması arasındaki farklılık istatistiksel olarak anlamlı bulunmuştur $(z=-4,723$; $p<.001)$. Söz konusu farklılık aktif olan grubun lehine gerçekleşmiştir. Aktif olarak tanımlanan grubun CP (konsantrasyon performansı) puanlarının pasif olarak tanımlanan gruptan anlamlı şekilde yüksek çıktığı belirlenmiştir.

Tablo 8. d2 Dikkat Testi FR (Şaşırma) Puanlarının Aktivite Değiş̧kenine Göre Farklılaşıp Farklılaşmadığını Belirlemek Amacıyla Yapılan Non-Parametrik Mann Whitney-U Testi Sonuçları

\begin{tabular}{|l|l|l|l|l|l|l|}
\hline Grup & $\mathbf{N}$ & $\bar{x}_{\text {sira }}$ & $\sum_{\text {Sira }}$ & $U$ & $z$ & $p$ \\
\hline Aktifler & 24 & 22,13 & 531,00 & & & \\
\hline Pasifler & 24 & 26,88 & 645,00 & 231,000 & $-1,182$ &, 237 \\
\hline Toplam & 48 & & & & & \\
\hline
\end{tabular}

Tabloda görüldüğü üzere, FR (şaşırma) puanlarının aktivite değişkenine göre farklılaşıp farklılaşmadığını belirlemek amacıyla yapılan non-parametrik Mann Whitney-U analizi sonucunda, aktif olan ve olmayan öğrencilerin sıralamalar ortalaması arasındaki farklılık istatistiksel olarak anlamlı bulunmamıştır $(z=-1,182 ; p>.05)$. 


\section{Dayanıklıık Açısından Karşılaştırma}

Tablo 9. d2 Dikkat Testi Toplam İşaretleme Sayısı (TN) Puanlarının Dayanıklılık Değişkenine Göre Farklılaşıp Farklılaşmadığını Belirlemek Amacıyla Yapılan Non-Parametrik Mann Whitney-U Testi Sonuçları

\begin{tabular}{|l|l|l|l|l|l|l|}
\hline Grup & $\mathbf{N}$ & $\bar{x}_{\text {sira }}$ & $\sum_{\text {Sira }}$ & $U$ & $z$ & $p$ \\
\hline Dayanık11 & 23 & 29,63 & 681,50 & & & \\
\cline { 1 - 5 } Dayanıks1z & 22 & 16,07 & 353,50 & 100,500 & $-3,463$ &, 001 \\
\hline Toplam & 45 & & & & & \\
\hline
\end{tabular}

Tabloda görüldüğü üzere, toplam işaretleme sayısı puanlarının dayanıklılık değişkenine göre farklılaşıp farklılaşmadığını belirlemek amaciyla yapılan non-parametrik Mann Whitney-U analizi sonucunda, dayanıklı olan ve olmayan öğrencilerin sıralamalar ortalaması arasındaki farklılık istatistiksel olarak anlamlı bulunmuştur $(z=-3,463$; $p<.001)$. Söz konusu farklılık dayanıklı olan grubun lehine gerçekleşmiştir. Dayanıklı olarak tanımlanan grubun toplam işaretleme sayısının dayanıksız olarak tanımlanan grubun sayısından anlamlı şekilde yüksek çıktığı belirlenmiştir.

Tablo 10. d2 Dikkat Testi Birinci Tür Hata (İşaretlemesi Gerekirken İşaretlemeden Atladığı d'ler) Puanlarının Dayanıklılık Değişkenine Göre Farklılaşıp Farklılaşmadığını Belirlemek Amacıyla Yapılan Non-Parametrik Mann Whitney-U Testi Sonuçları 


\begin{tabular}{|l|l|l|l|l|l|l|}
\hline Grup & $\mathbf{N}$ & $\bar{x}_{\text {sira }}$ & $\sum_{\text {Sira }}$ & $U$ & $z$ & $p$ \\
\hline Dayanıklı & 23 & 18,91 & 435,00 & & & \\
\cline { 1 - 5 } Dayanıks1z & 22 & 27,27 & 600,00 & 159,000 & $-2,143$ &, 032 \\
\hline Toplam & 45 & & & & & \\
\hline
\end{tabular}

Tabloda görüldüğü üzere, birinci tür hata (işaretlemesi gerekirken işaretlemeden atladığı d'ler) puanlarının dayanıklılık değişkenine göre farklılaşıp farklılaşmadığını belirlemek amacıyla yapılan non-parametrik Mann Whitney-U analizi sonucunda, dayanıklı olan ve olmayan öğrencilerin sıralamalar ortalaması arasındaki farklılık istatistiksel olarak anlamlı bulunmuştur $(z=-2,143$; $p<.001)$. Söz konusu farklılık dayanıksız olan grubun lehine gerçekleşmiştir. Dayanıklı olarak tanımlanan grubun birinci tür hata (işaretlemesi gerekirken işaretlemeden atladığı d'ler) puanlarının dayanıksız olarak tanımlanan grubun puanlarından anlamlı şekilde düşük çıktığı belirlenmiştir.

Tablo 11. d2 Dikkat Testi İkinci Tür Hata (İşaretlememesi Gerekirken İşaretlemiş Olduğu Figürler) Puanlarının Dayanıklılık Değişkenine Göre Farklılaşıp Farklılaşmadığını Belirlemek Amacıyla Yapılan Non-Parametrik Mann Whitney-U Testi Sonuçları 


\begin{tabular}{|l|l|l|l|l|l|l|}
\hline Grup & $\mathbf{N}$ & $\bar{x}_{\text {sira }}$ & $\sum_{\text {Sira }}$ & $U$ & $z$ & $p$ \\
\hline Dayanıkl1 & 23 & 19,74 & 454,00 & & & \\
\cline { 1 - 5 } Dayanıks1z & 22 & 26,41 & 581,00 & \multirow{2}{*}{178,000} & $-1,713$ &, 087 \\
\hline Toplam & 45 & & & & & \\
\hline
\end{tabular}

Tabloda görüldüğü üzere, ikinci tür hata (işaretlememesi gerekirken işaretlediği figürler) puanlarının Dayanıklılık değişkenine göre farklılaşıp farklılaşmadığını belirlemek amacıyla yapılan non-parametrik Mann Whitney-U analizi sonucunda, dayanıklı olan ve olmayan öğrencilerin sıralamalar ortalaması arasındaki farklılık istatistiksel olarak anlamlı bulunmamıştır $(z=-1,713 ; p>.05)$.

Tablo 12. d2 Dikkat Testi TN-E (Toplamdan Hataların Çıkarılmış Hali) Puanlarının Dayanıklılık Değişkenine Göre Farklılaşıp Farklılaşmadığını Belirlemek Amacıyla Yapılan Non-Parametrik Mann Whitney-U Testi Sonuçları

\begin{tabular}{|l|l|l|l|l|l|l|}
\hline Grup & $\mathbf{N}$ & $\bar{x}_{\text {sira }}$ & $\sum_{\text {Sira }}$ & $U$ & $z$ & $p$ \\
\hline Dayan1k11 & 23 & 31,61 & 727,00 & & & \\
\cline { 1 - 5 } Dayan1ks1z & 22 & 14,00 & 308,00 & 55,000 & $-4,496$ &, 000 \\
\cline { 1 - 4 } Toplam & 45 & & & & & \\
\hline
\end{tabular}

Tabloda görüldügü üzere, TN-E (toplamdan hataların çıkarılmış hali) puanlarının dayanıklılık değişkenine göre farklılaşıp farklılaşmadığını belirlemek amacıyla yapılan non-parametrik Mann Whitney-U 
analizi sonucunda, dayanıklı olan ve olmayan öğrencilerin sıralamalar ortalaması arasındaki farklılık istatistiksel olarak anlamlı bulunmuştur $(z=-4,496 ; p<.001)$. Söz konusu farklılık dayanıklı olan grubun lehine gerçekleşmiştir. Dayanıklı olarak tanımlanan grubun TN-E (toplamdan hataların çıkarılmış hali) puanlarının dayanıksız olarak tanımlanan gruptan anlamlı şekilde yüksek çıktığı belirlenmiştir.

Tablo 13. d2 Dikkat Testi CP (Konsantrasyon Performansı) Puanlar1nın Dayanıklılık Değişkenine Göre Farklılaşıp Farklılaşmadığını Belirlemek Amacıyla Yapılan Non-Parametrik Mann Whitney-U Testi Sonuçlar1

\begin{tabular}{|l|l|l|l|l|l|l|}
\hline Grup & $\mathbf{N}$ & $\bar{x}_{\text {sira }}$ & $\sum_{\text {Sira }}$ & $U$ & $z$ & $p$ \\
\hline Dayan1kl1 & 23 & 32,57 & 749,00 & & & \\
\cline { 1 - 5 } Dayan1ks1z & 22 & 13,00 & 286,00 & 33,000 & $-4,996$ &, 000 \\
\hline Toplam & 45 & & & & & \\
\hline
\end{tabular}

Tabloda görüldüğü üzere, CP (konsantrasyon performansı) puanlarının dayanıklılık değişkenine göre farklılaşıp farklılaşmadığını belirlemek amacıyla yapılan non-parametrik Mann Whitney-U analizi sonucunda, dayanıklı olan ve olmayan öğrencilerin sıralamalar ortalaması arasındaki farklılık istatistiksel olarak anlamlı bulunmuştur $(z=-4,996 ; p<.001)$. Söz konusu farkl1l1k dayanıklı olan grubun lehine gerçekleşmiştir. Dayanıklı olarak tanımlanan grubun CP (konsantrasyon performansı) puanlarının dayanıksız olarak tanımlanan gruptan anlamlı şekilde yüksek çıktığı belirlenmiştir. 
Tablo 14. d2 Dikkat Testi FR (Şaşırma) Puanlarının Dayanıklılık Değişkenine Göre Farklılaşıp Farklılaşmadığını Belirlemek Amacıyla Yapılan Non-Parametrik Mann Whitney-U Testi Sonuçları

\begin{tabular}{|l|l|l|l|l|l|l|}
\hline Grup & $\mathbf{N}$ & $\bar{x}_{\text {sira }}$ & $\sum_{\text {Sira }}$ & $U$ & $z$ & $p$ \\
\hline Dayanıkl1 & 23 & 22,72 & 522,50 & & & \\
\cline { 1 - 5 } Dayanıks1z & 22 & 23,30 & 512,50 & 246,500 &,- 149 &, 882 \\
\hline Toplam & 45 & & & & & \\
\hline
\end{tabular}

Tabloda görüldüğü üzere, FR (şaşırma) puanlarının dayanıklılık değişkenine göre farklılaşıp farklılaşmadığını belirlemek amacıyla yapılan non-parametrik Mann Whitney-U analizi sonucunda, dayanıklı olan ve olmayan öğrencilerin sıralamalar ortalaması arasındaki farklılık istatistiksel olarak anlamlı bulunmamıştır $(z=-1,182 ; p>.05)$.

\section{Şifre ve Dikkat Puanları İlişkisi}

Tablo 15. $d 2$ Dikkat Testi Puanlarının Şifre Testi Puanları İle İlişkisini Belirlemek Amacıyla Yapılan Pearson Çarpım Moment Korelasyon Analizi Sonuçları 


\begin{tabular}{|l|c|c|c|}
\hline \multirow{2}{*}{ Puanlar } & \multicolumn{3}{|c|}{ Şifre Puanı } \\
\cline { 2 - 4 } & N & r & P \\
\hline Toplam İşaretleme Sayısı & 124 &, 716 &, 000 \\
\hline Birinci Tür Hata & 124 &, 120 &, 186 \\
\hline İkinci Tür Hata & 124 &,- 082 &, 368 \\
\hline TN-E & 124 &, 679 &, 000 \\
\hline CP & 124 &, 560 &, 000 \\
\hline FR & 124 &,- 076 &, 404 \\
\hline
\end{tabular}

Tabloda görüldüğü üzere, dikkat testi puanlarının şifre testi puanları ile ilişkisini belirlemek amacıyla yapılan Pearson çarpım moment korelasyon analizi sonucunda şifre puanları ile toplam işaretleme puanları arasında pozitif yönlü $(r=, 716 ; p<.001)$; şifre puanları ile TN-E puanları pozitif yönlü $(r=, 679 ; p<.001)$; şifre puanları ile CP puanları pozitif yönlü $(r=, 560 ; p<.001)$ anlamlı bir ilişki olduğu belirlenmiştir. Diğer puanlar arasındaki ilişkiler istatistiksel olarak anlamlı bulunmamıştır ( $\mathrm{p}>.05)$.

\section{Güvenirliğe Ait Bulgular}

Güvenirlik çalışması için test- tekrar- test yöntemi kullanılmıştır.

Tablo 16. d2 Dikkat Testinin Tutarlılık (Devaml111k) Katsayısını Belirlemek Amacıyla Test-Tekrar-Test Puanları Arasındaki İlişkinin Anlamlılığını Belirlemek Üzere Yapılan Pearson Çarpım Moment Korelasyon Analizi Sonuçları 


\begin{tabular}{|l|c|c|c|}
\hline \multirow{2}{*}{ Alt Puanlar } & \multicolumn{3}{|c|}{ Değerler } \\
\cline { 2 - 4 } & $\boldsymbol{N}$ & $\boldsymbol{r}$ & $\boldsymbol{P}$ \\
\hline TN & 124 &, 885 &, 000 \\
\hline E1 & 124 &, 884 &, 000 \\
\hline E2 & 124 &, 761 &, 000 \\
\hline TN-E & 124 &, 831 &, 000 \\
\hline CP & 124 &, 877 &, 000 \\
\hline FR & 124 &, 570 &, 000 \\
\hline
\end{tabular}

Tablodan anlaşılacağı üzere, dikkat testinin tutarlılık (devamlılık) katsayısını belirlemek amaciyla test-tekrar test puanları arasındaki ilişkinin anlamlılığını test etmek için yapılan Pearson çarpım moment korelasyon analizi sonucunda söz konusu ilişkiler TN puanları için $(r=, 885 ; p<.001)$; E1 puanları için $(r=, 884 ; p<.001)$; E2 puanları için $(r=, 761 ; p<.001)$; TN-E puanları için $(r=, 831 ; p<.001)$; CP puanları için $(r=, 877 ; p<.001)$; FR puanları için $(r=, 570 ; p<.001)$ pozitif yönde ve anlamlı bulunmuştur. Bu değerler dikkat testinin bütün alt boyutlarının devamlılık açısından güvenilir olduğunu göstermektedir.

\section{Sonuç ve Tartışma}

Dikkat öğrenme sürecinde ilk basamak olması açısından önemlidir. Bireylerin dikkat düzeylerindeki farklılıklar eğitim, endüstri, sağlık ve savunma sanayi gibi alanlardaki görevlerde avantaj ya da dezavantaj yaşayabilmelerine neden olabilmektedir. Öğrenme problemlerinde (Khayat, 1985; Eser, 1987; Warnke, 1990; Ihlefeld ve Finck, 1990), dikkat gerektiren görevler için uygun personel seçiminde 
ve bazı sağlık problemlerin tanılanmasında bireyin dikkat düzeyini saptayabilmek önemlidir. Bu nedenle geçerlik ve güvenirliği yüksek, uygulanması ve değerlendirilmesi konusunda kullanışlı ve ekonomik ölçme araçlarına ihtiyaç vardır. d2 Dikkat Testi bu koşulları karşılaması ve geniş bir yaş grubunda uygulanabilmesi nedeniyle önemli bir testtir.

Diğer dikkat testleri ile kıyaslandığında d2 Dikkat Testi’nin süresinin kısa olması, grup testi olarak uygulanabilirliği, yüksek güvenirliği, temsili örneklemlere dayalı norm tabloları bu testin avantajları olarak gösterilmektedir (Toker, 1993).

d2 Dikkat Testi’nin değerlendirilmesi sırasında TN, E1, E2, CP, FR ve TN-E puanları esas alınmaktadır. Toplam işaretleme sayısının (TN) yüksekliği seçici dikkat yetisinin, dikkatin sürdürülebilirliğinin, yüksek motivasyonun ve psikomotor hızın yüksekliğini, E1 türü hataların fazlalığı seçici dikkat düzeyindeki düşüklüğü ve ortaya konulan performansın kalitesinin yetersizliğini, E2 tür hataların fazlalığı özel öğrenme güçlüğü ve mental retardasyonu, dikkatsizliği, yönergeye uyumda zorlanmayı, görsel ayrımlaştırmadaki problemleri, TN-E puanlarının yüksekliği ortaya konulan performansın kaliteli oluşunu, psikomotor hız ve seçici dikkat arasındaki dengeyi, CP puanları psikomotor hızdaki istikrarı ve yapılan işin kalitesini, FR'nin yüksek olması ise çoğu kez düşük motivasyonu ve psikomotor hızdaki istikrarsızlığı düşündürmektedir (Brickenkamp ve Zillmer, 1998).

Psiko-motor hiz ise belli bir sürede niceliksel olarak ne kadar ilerleme kaydedildiğini ifade etmektedir. Psiko-motor hızın gelişebil- 
mesi için dikkatin kayabilme özelliğinin de gelişmesi gerektiği düşünülebilir.

d2 Dikkat Testi'nin tutarlılık (devamlılık) katsayısını belirlemek için yapılan çalışmada pozitif yönde ve anlamlı bulunmuştur (TN $r=, 885$; E1 $r=, 884$; E2 $r=, 76$; TN-E $r=, 831$; CP $r=, 877$; FR $r=, 570$ ) Bu bulgular Büttner (1968) ve Toker (1993), çalışmaları ile paralellik göstermektedir.

Güvenirlik katsayısının yorumlanmasında en önemli ölçüt ne düzeyde bir korelasyon katsayısının yeterli olacağıdır. Buradaki temel ölçüt ölçeğin hangi amaçla kullanılacağıdır. Polit ve Hungler’e (1997) göre .70 bir çok araştırmada doyurucu olmakla birlikte asgari .85-.95 aralığının seçilmesi gereklidir. Yapılan çalışmada elde edilen güvenirlik katsayıları FR puanı dışında genel olarak bu değerleri karşılamaktadır. FR değerleri testin orjinalinde de .49-.52 arasında bulunmuştur. d2'nin orjinalinde test tekrar test güvenirliği .92 olarak bulunmuştur. Farklı araştırmacılar tarafından yapılan diğer çalışmalarda da yüksek korelasyonlar bulunmuştur ( $\mathrm{r}=.90$ ve r=.94) (Brickenkamp ve Zillmer, 1998).Yapılan çalışmada testin diğer puan türlerinde de testin orjinali ile paralellik gösteren sonuçlar elde edilmiştir.

Devamlılık katsayısının hesaplanmasında temel sorun iki ölçme arasında ne kadar süre geçeceğidir? Bu konuda öncelikli olarak ölçeğin ölçtüğü özellik açısından önemli değişikliklerin olmaması gerekir. Ayrıca birinci uygulamayı hatırlayacak kadar kısa olmamalıdır. $\mathrm{Bu}$ durum değişik kaynaklarda, ölçülen özelliğe bağlı olarak 2-6 hafta arası 
olarak önerilmektedir (McLaughlin ve Marasculio, 1990; Ergin, 1995) Yapılan çalışmada iki uygulama arasında sekiz hafta geçmiştir. $\mathrm{Bu}$ durum öğrenmeden kaynaklanan avantajları ortadan kaldırmıştır.

Rapp (1982), dikkat süresinin okula başlandığı ilk yıllarda 10 dakika olduğunu, ileriki yıllarda yaş değişkenine bağlı olarak arttığını belirtmiştir. Rapp, dikkat süresinin 10 yaşında 20 dakika, 14 yaşında 30 dakika olduğunu vurgulamaktadır. d2 Dikkat Testi yaklaşık sekiz dakikada uygulanabilen bir testtir. Bu durum testin yaş değişkenine bağlı olarak geçerliğini etkilememektedir.

Geçerlik çalışmalarında WISC-R alttestlerinin tamamı ile d2 Dikkat Testi’nin bütün puan türleri arasında pozitif yönlü anlamlı ilişki bulunmuştur. Her iki testin de ölçtüğü özellikler arasında yoğunlaşabilme, anlık tepki verebilme, psiko-motor hız ve görsel analiz-sentez gibi benzer bilişsel fonksiyonların olması bu durumun nedeni olabilir.

Geçerliği belirlemede ikinci ölçüt olan öğretmen görüşleri (öğrencilerin aktif-pasif oluşlarına yönelik değerlendirmeleri ve dayanıkl1lık-kolay pes etmemeye ilişkin görüşleri) ile d2 Dikkat Testi puanları arasında aktiflik-pasiflik değişkenine bakıldığında E1 hata türü, E2 hata türü ve FR puanları arasında anlamlı ilişki bulunmamış, TN, TN-E, CP puanlarında aktif olan gruplar lehine anlamı farklar bulunmuştur. Dayanıkl11ık-kolay pes etmeme değişkenine bakıldığında ise E2 hata türü ve FR puanları ile d2 Dikkat Testi sonuçları arasında anlamlı ilişki bulunmamışken TN, TN-E, E1 ve CP puanları arasında dayanıklı-kolay 
pes etmeyen öğrenciler lehine anlamlı farklılıklar belirlenmiştir.

Şifre ve d2 puanları arasındaki ilişkiyi belirlemek amacıyla yapılan Pearson Momentler Çarpımı Korelasyon Katsayısı'na göre Şifre testi ile d2 Dikkat Testi TN, TN-E ve CP puanları arasında pozitif yönlü anlamlı ilişki bulunmuşken E1, E2 ve FR puanları arasında anlamlı ilişkiler bulunmamıştır. Şifre testi ve d2 Dikkat Testi'nin birim zamanda niceliksel olarak ortaya konulan performansları ölçmesinin $\mathrm{TN}$, TN-E ve CP puanları arasında pozitif yönlü anlamlı ilişkinin çıkmasına neden olduğu düşünülebilir. E1, E2 ve FR türü hata değişkenlerinin görevin niteliğini ölçmesinin, belirtilen testlerin ise nitelikten ziyade niceliği ölçmesinin; E1, E2 ve FR puan türleri arasında anlamlı ilişki bulunmamasına neden olabileceği düşünülebilir.

d2 testinin orjinalinin geçerlik çalışmasında d2, Pauli Testi, KLT ile önemli ilişki göstermiştir. Pauli testi ile .51 ilişki katsayısı hesaplanmıştır. KLT ile ilişki katsayısı .58 olarak bulunmuştur (Karaduman, 2004). Ayrıca sınıf öğretmenlerinden sınıflarındaki en aktif, en pasif ve dayanıklı (kolay pes etmeyen-sebatlı) ve dayanıklı olmayan öğrencileri seçmeleri istenmiş bu özellikleri ile psiko-motor hızları ve olası hata oranları konusunda yordamalarda bulunulmaya çalışılmıştır. t testi sonucunda aktif olma ile psiko-motor hiz ve az hata yapma ile dayanıklılık arasında anlamlı ilişkiler bulunmuştur. Dayanıklı olma-olmama (irade-kolay pes etmeme) özellikleri ile psiko-motor hiz ve aktif olma-olmama ile hata oranları arasında ise anlamlı bir ilişki bulunmamıştır. Aktif olan öğrencilerin etkinliğe başlama ve sürdürme konusundaki motivasyonları psikomotor hızın artmasına katkı sağlamış 
olabilir. Dayanıklı öğrencilerin görev esnasında görevin sonuna kadar ara vermeden, ertelenmeden ve atlamadan aynı kalitede gidebilmelerinin hata miktarının düşük olmasına neden olabileceği düşünebilir. Dayanıklı öğrencilerin hatadan kaçınmak için daha dikkatli davranmaları psikomotor hızın niceliğini düşüren, niteliğini ise artıran bir özellik olabilir. Aktif olan öğrencilerin birim zamanda niceliksel olarak daha fazla performans gösterme gayretleri dikkatsizlik kaynaklı hata sayısındaki artışa neden olabilir.

Geçerlilik ile sonuçlar testin orjinalindeki sonuçlara ve Bates ve Lemay (2004)'in d2 Dikkat Testi’nin Amerikan örnekleminde yapı geçerliğini belirlemek amacıyla d2 Dikkat Testi sonuçlarını 'WAIS' , 'Digit Symbol Substition Test A-B' ve 'Trail Making’ testi vb. ile karşılaştırmaları sonucunda testin görsel tarama (seçici dikkat) ve psiko-motor hızı ölçmede geçerli bir ölçme aracı olduğu sonucuyla benzerlik göstermektedir. Geçerlik çalışmasından elde edilen sonuçlar TN-E puanlarında Culberson ve Zillmer (1998)'in Trail Making Test A,B (-.26 ve -.29), SDMT (.47) ve Stroop Testi (.34) ve TOL Testi (-.44,-.34,-.43 ve -.36) sonuçlarının ise üzerindedir.

Sonuç olarak, d2 Dikkat Testi’nin psikometrik özellikleri kabul edilir düzeydedir, yani bu test Türkiye'de yürütülecek araştırmalarda kullanılabilir niteliktedir.

d2 Dikkat Testi'nin sınırlılığı, dikkat olgusunun sadece bir bölümünün ölçülmesidir. Bu nedenle test başka ölçülerle birlikte uygulanmalıdır (Weiss, 1975). Bu sınırlılık nedeniyle sadece test sonuçla- 
rına göre bireyin dikkat düzeyi bir etiketleme yapmaktan kaçınmak önerilebilir.

Testin farklı yaş grupları için de geçerlik güvenirlik çalışmaları, cinsiyete dayalı ve okul türlerine göre karşılaştırmalar da yapılabilir.

\section{Kaynakça}

Bates, M. E. ve Lemay. E. (2004). The d2 test of attention: construct validity and extensions in scoring techniques. Journal of the International Neuropsychological Society,10(3), 392-400.

Brickencamp, R. (1981). d2 aufmerksamkeits- belastungs. Test: handanweisung. Göttingen: Hofrere.

Brieckamp, R. ve Zillmer, E. (1998). The d2 test of attention. Seattle,Washington: Hogrefe \& Huber Publishers.

Broadbent, D. E. (1958). Perception and communication. New York: Pergamon.

Bower, G. H. ve Hilgard, E. R. (1981). Theories of learning. Englewood Cliffs. N.J: Prentice-Hall.

Büttner, C. (1968). Retestreliabilititatskontrolle des aufmerksamkeitsbelastungs-tests $d 2$ (Test-re-test reliability control of the $d 2$ test of attention). Unpublished manuscript. Semesterarbeit. Marburg/Lahn:Institute for Psychology. Universitat of Marburg.

Büyüköztürk, Ş. (2003). Sosyal bilimler için veri analizi el kitabı. 
Ankara: PegemA Yayınc1lık.

Büyüköztürk, Ş., Çakmak, E. K., Akgün, Ö. E., Karadeniz, Ş. ve Demirel, F. (2008). Bilimsel araştırma yöntemleri. Ankara: PegemA Yayınları.

Carey, L. M. (1988). Measuring and evaluation school learning. London: Allyn and Bacon Inc.

Culbertson, W. C. ve Zillmer, E. A. (1998). The tower of London Drexel University: A standardized approach to assensing executive functioning in children. Archieves of Clinical Neuropsychology, 13(3), 285-302.

Çağlar, E. (2003). d2 Dikkat Testinin sporcularda güvenirliği ve geçerliği. Yayınlanmamış doktora tezi, Hacettepe Üniversitesi Sağlık Bilimleri Enstitüsü.

Eser, K. H. (1987). Reliabilitats und validitatsaspekte des aufmerksamkeits-belastungs- tests (test $\mathrm{d} 2$ ) bei verhaltengsgestörten kindern und jugendlichen (reliability and validity aspects of the $\mathrm{d} 2$ test of attention among children and adolescents with behavior problems). Diagnostica, 33, 74-80.

Ergin, D. Y. (1995). Ölçeklerde geçerlik ve güvenirlik. M. ̈̈. Ĕ̆itim Bilimleri Dergisi, 7, 125-148.

Inlefeld, U. ve Finck, W. (1990). Selbstbild und indivuelle subjectivitat (The self and individual subjectivity). Psychologie für die 
praxis, 8, 219-228.

Karaduman, B. D. (2004). Dikkat toplama ĕgitim programının ilköğretim 4. ve 5. sinıf ögrrencilerinin dikkat toplama düzeyi, benlik algısı ve başarı düzeylerine etkisi. Yayınlanmamış Doktora Tezi, Ankara Üniversitesi. Eğitim Bilimleri Enstitüsü.

Karakaş, S. (1997). A descriptive framework for information processing: An integrative approach. International Journal of Psychophysiology, 26(1-3), 353- 368.

Khayat, C. (1985). Neingungsstruktur intelligenz, konzentration und leistungmotivation von sonderschulabgamgem. Eine bestandaufnahme (Disposition intelligence, concentration and performance motivation among special education school children. An inventory). Vienna: Faculty of Basic and Integrative Sciences. University of Vienna.

Kolb, B. ve Windshaw, I. Q. (1996). Attention. Imagery and Consciosness. Fundementals of Human Neuropsychology (4. bask1). New York: W.H. Freeman and Company.

Linn, R. L. ve Gronlund, N. E. (1995). Measurement and assesment in teaching (7. bask1). New Jersey: Prencite-Hall.Inc.

McLaughlin, F. E. ve Marasculio, L. A. (1990). Advanced nursing and health care research: Quantification approaches. Philedelphia: W.B.Saunders Company. 
Meeker, W. Q. (1998). Statistical methods for reliability data. New Jersey: Wiley.

Mesulam, M. M. (2004). Dikkat şebekeleri. konfüzyonel durumlar ve ihmal sendromlart: Davranışsal ve kognitif nörolojinin ilkeleri. (H. Gürvit, Çev.). İstanbul: Yelkovan Yayınları.

Öner, N. (1997). Türkiye'de kullanılan psikolojik testler: Bir başvuru kaynă̆ı (3.baskı). İstanbul: Boğaziçi Üniversitesi Yayınları.

Polit, D. ve Hungler, B. (1997). Essentials of nursing research: methods, appraisal, and utilization (4. baskı). Philadelphia: J. B. Lippincott Company.

Rapp, G. (1982). Aufmerksamkeit und konzentration: erklaerungsmodelle, störungen, handlungsmöglichkeiten. Bad Heilbrunn: Klinkhart.

Sergeant, J. (1996). A theory of attention: An information processing perspective. G. R. Lyon ve N.A. Krasnegor, (Ed.), Attention, memory and executive function içinde (57-69). Baltimore: Brooks.

Spreen, O. ve Strauss, E. (1998). A compendium of neuropsychological test (2. bask1). New York: Oxford University Press.

Tezbaşaran, A. (1997). Likert tipi ölçek geliştirme kılavuzu. Psikoloji Derneği Yayınları, Ankara: Özyurt Matbaası. 
Thorndike, R. M., Cunnigham, G. K. Thorndike, R. L. ve Hagen, E. P. (1991). Measurement and evaluation in psychology and education (5. baskı). New York: Machimillian Publishing.

Toker, M. Z. (1993). Visual algı testi d2'nin geçerlik ve güvenirlik çalışması. Yayınlanmamış yüksek lisans tezi, Boğaziçi Üniversitesi.

Warnke, A. (1990). Legasthenie und hirnfunktion. Neuropsychologische befunde zur visuellen informations-verarbeitung (Dislexia and brain function. Neuropsychological findings in the processing of visual information). Bern: Huber. 
